\title{
All-ceramic, bi-layered crowns supported by zirconia implants: three-year results of a prospective multicenter study
}

\author{
Spies, Benedikt C ; Balmer, Marc ; Jung, Ronald E ; Sailer, Irena ; Vach, Kirstin ; Kohal, Ralf-Joachim
}

\begin{abstract}
OBJECTIVES: To determine the clinical and patient-reported outcomes of bi-layered, all-ceramic posterior single crowns (SCs) supported by zirconia implants in an uncontrolled, prospective, multicenter study. METHODS: In two centers, 60 patients received 71 one-piece zirconia oral implants to be restored with either SCs $(n=49)$ or three-unit fixed dental prostheses $(n=11)$. Of these patients, 45 implants were restored with all-ceramic, zirconia-based posterior SCs (one per patient). Survival rates of implants and reconstructions were assessed, and technical success was evaluated according to modified U.S. Public Health Service (USPHS) criteria. Furthermore, patient-reported outcome measures (PROMs) were assessed by applying visual analog scales (VAS). Kaplan-Meier (KM) plots and log-rank tests were used for success/survival analyses. The Wilcoxon matched-pairs signed-rank test was used to evaluate time effects on response variables (PROMs, USPHS criteria). RESULTS: Forty patients with 40 SCs could be evaluated after $36.7 \pm 1.2$ months. No SC was replaced, resulting in $100 \%$ survival. The KM success estimate was $87.5 \%$ (two chippings, one restoration margin, and one contour were rated Charlie). In general, the incidence of chipping $(p=.0005)$ and occlusal roughness $(p=.0003)$ was frequent. Compared with the pre-treatment patient surveys (67-93\%), all surveys at prosthetic delivery except for speech $(p=.139)$ showed significantly improved VAS scores $(81-94 \%$; $\mathrm{p}<.0001)$. Thereafter, no decrease in satisfaction could be observed over time until the 3-year follow-up (86-93\%; $\mathrm{p} \geq .390$ ). CONCLUSION: Veneered, zirconia-based SCs supported by zirconia implants satisfied patients' needs highly. However, significant incidence of chipping and roughness of the veneering ceramic may compromise the clinical long-term outcome for this indication. CLINICAL SIGNIFICANCE: Posterior, zirconia-based SCs supported by zirconia oral implants entirely survived the follow-up period of 3 years, but two major chippings, one a significant marginal opening and one pronounced over-contouring, resulted in a reduced $\mathrm{KM}$ success estimate of $87.5 \%$ after 36 months of observation.
\end{abstract}

DOI: https://doi.org/10.1016/j.jdent.2017.09.008

Posted at the Zurich Open Repository and Archive, University of Zurich ZORA URL: https://doi.org/10.5167/uzh-142332

Journal Article

Accepted Version

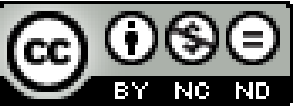

The following work is licensed under a Creative Commons: Attribution-NonCommercial-NoDerivatives 4.0 International (CC BY-NC-ND 4.0) License.

Originally published at:

Spies, Benedikt C; Balmer, Marc; Jung, Ronald E; Sailer, Irena; Vach, Kirstin; Kohal, Ralf-Joachim (2017). Allceramic, bi-layered crowns supported by zirconia implants: three-year results of a prospective multicenter study. 
Journal of Dentistry, 67:58-65.

DOI: https://doi.org/10.1016/j.jdent.2017.09.008 


\section{All-ceramic, bi-layered crowns supported by zirconia implants: Three-year results of a prospective multicenter study}

Short title: Ceramic crowns on zirconia implants

Benedikt C. Spies (Associate Professor) ${ }^{\mathrm{a}}$, Marc Balmer (Assistant Professor) $^{\mathrm{b}}$, Ronald E. Jung $^{b}$ (Associate Professor), Irena Sailer (Chair) ${ }^{c}$, Kirstin Vach (Statistician) ${ }^{d}$, RalfJoachim Kohal (Associate Professor) ${ }^{\mathrm{a}}$

a) Department of Prosthetic Dentistry, Center for Dental Medicine, Medical CenterUniversity of Freiburg, Faculty of Medicine, University of Freiburg, Hugstetter Str. 55, D-79106 Freiburg, Germany

b) Clinic of Fixed and Removable Prosthodontics and Dental Material Science, Center of Dental Medicine, University of Zurich, Plattenstr. 11, CH-8032 Zurich, Switzerland

c) Division of Fixed Prosthodontics and Biomaterials, University Clinics for Dental Medicine, University of Geneva, Geneva, 19 rue Barthélemy-Menn, CH-1205 Genf, Switzerland

d) Institute for Medical Biometry and Statistics, Center for Medical Biometry and Medical Informatics, Medical Center - University of Freiburg, Faculty of Medicine, University of Freiburg, Hebelstr. 11, D-79104 Freiburg, Germany

Corresponding author:

Benedikt Christopher Spies

Medical Center - University of Freiburg, Department of Prosthetic Dentistry

Hugstetter Straße 55, 79106 Freiburg, Germany

Phone: +49 761270 47680, Fax: +49 761270 49250;

e-mail: benedikt.spies@uniklinik-freiburg.de

This investigation was supported by VITA Zahnfabrik, Bad Säckingen, Germany. 


\begin{abstract}
Objectives: To determine the clinical and patient-reported outcomes of bi-layered, all-ceramic posterior single crowns (SCs) supported by zirconia implants in an uncontrolled, prospective, multicenter study.
\end{abstract}

Methods: In two centers, 60 patients received 71 one-piece zirconia oral implants to be restored with either SCs $(n=49)$ or three-unit fixed dental prostheses $(n=11)$. Of these patients, 45 implants were restored with all-ceramic, zirconia-based posterior SCs (one per patient). Survival rates of implants and reconstructions were assessed, and technical success was evaluated according to modified U.S. Public Health Service (USPHS) criteria.

Furthermore, patient-reported outcome measures (PROMs) were assessed by applying visual analog scales (VAS). Kaplan-Meier (KM) plots and log-rank tests were used for success/survival analyses. The Wilcoxon matched-pairs signed-rank test was used to evaluate time effects on response variables (PROMs, USPHS criteria).

Results: Forty patients with 40 SCs could be evaluated after $36.7 \pm 1.2$ months. No SC was replaced, resulting in $100 \%$ survival. The KM success estimate was $87.5 \%$ (two chippings, one restoration margin, and one contour were rated Charlie). In general, the incidence of chipping $(\mathrm{p}=.0005)$ and occlusal roughness $(\mathrm{p}=.0003)$ was frequent. Compared with the pre-treatment patient surveys (67-93\%), all surveys at prosthetic delivery except for speech ( $\mathrm{p}$ $=.139)$ showed significantly improved VAS scores $(81-94 \% ; \mathrm{p}<.0001)$. Thereafter, no decrease in satisfaction could be observed over time until the 3-year follow-up (86-93\%; $\mathrm{p} \geq$ .390).

Conclusion: Veneered, zirconia-based SCs supported by zirconia implants satisfied patients' needs highly. However, significant incidence of chipping and roughness of the veneering ceramic may compromise the clinical long-term outcome for this indication.

German Clinical Trials Register (ID: DRKS00000226)

\title{
Clinical significance
}

Posterior, zirconia-based SCs supported by zirconia oral implants entirely survived the follow-up period of 3 years, but two major chippings, one a significant marginal opening and one pronounced over-contouring, resulted in a reduced KM success estimate of $87.5 \%$ after 36 months of observation. 
Keywords [MeSH]: Ceramics; Dental porcelain; Crown; CAD-CAM; Dental implant; Zirconia

\section{Introduction}

The German Oral Health Study (DMS) periodically collects key oral health and dental care indicators (e.g., mucosal abnormalities, caries, periodontitis, and tooth loss) across four age cohorts in a cross-sectional, socio-epidemiological design [1]. The fifth edition (DMS V), published in 2016, showed a prevalence of 2.1 and 11.1 missing teeth in younger adults (aged 35 to 44 years) and younger elderly (aged 65 to 74 years), respectively [2, 3]. In both groups, tooth loss was mostly located in the area of premolars and molars. When it is time to replace these teeth located in load-bearing areas, several treatment options, ranging from fixed to removable prostheses, are available.

In the case of single tooth gaps with neighboring teeth worth preserving, a fixed dental prosthesis (FDP) is one of the most chosen treatment options. This type of restoration represents a cost- and time-effective treatment with a favorable outcome. Comparing a recent review of the literature analyzing the clinical outcome of tooth-supported FDPs [4] with another one published 13 years ago [5], an obvious trend toward all-ceramic restorations can be observed. Besides technical complications observed in zirconia-based FDPs (high incidence of veneer chippings), supporting teeth are at risk of biological complications such as secondary caries or loss of vitality and subjected to an extensive removal of tooth structure [6]. Therefore, an implant-supported single crown (SC) might be a less invasive treatment option to prevent adjacent teeth from biological complications.

Single implant treatment can be considered a predictable treatment with high survival rates in the long term [7]. To date, not only the restoration but also the implant can be fabricated out of a ceramic material, allowing for a completely metal-free approach Oral implants made from yttria-stabilized tetragonal zirconia polycrystals (Y-TZP) proved to be reliable in prospective clinical evaluations with an outcome comparable to titanium implants [8]. Regrettably, data on the restoration of these implants are scarce. Because market-available zirconia implants are mostly designed as one-piece implants comprising an endosseous, transmucosal, and intraoral part in a single piece, the restoration has to be cemented to the implant abutment comparable to tooth-supported reconstructions. Especially in posterior regions, the same polycrystalline ceramic material (Y-TZP) as used for ceramic implant 
production proved to be a reliable substructure for the fabrication of highly esthetic, implantsupported, bi-layer crowns [9]. For both tooth- and implant-supported, zirconia-based SCs, survival rates seem to be comparable to those of conventional porcelain-fused-to-metal (PFM) crowns [10]. However, for posterior zirconia-based bilayer restorations in particular, and for implant-supported restorations in general, the most common technical reason for failure is fracture of the veneering material $[10,11]$. The lack of a periodontal ligament, the rigidity of implants, and impaired proprioception might be responsible for higher chipping ratios in implant-supported restorations [12].

Several suggestions were made for improving the chipping resistance of zirconia-based restorations [13], among others addressing the phase composition of the veneering ceramic. In a recent clinical trial evaluating the restoration of zirconia oral implants with zirconia-based SCs and FDPs, a lacking crystalline phase of the veneering ceramic resulting in reduced flexural strength was considered one of the major factors contributing to an unacceptable occurrence of severe veneer fractures resulting in a high failure rate of $23.4 \%$ after 5 years of observation [14]. Therefore, the aim of this study was to determine the clinical and patientreported outcomes of bi-layered, all-ceramic, posterior single crowns (SCs) comprising CAD/CAM-fabricated zirconia frameworks hand-layered with a leucite-reinforced feldspathic ceramic of increased flexural strength and a slightly higher mismatch of the coefficient of thermal expansion (framework > veneer, resulting in a more pronounced compression stress in the veneering ceramic) supported by zirconia implants. 


\section{Materials and Methods}

\section{Study design}

This multicenter study represents a prospective cohort investigation. The included centers were (1) Medical Center, University of Freiburg (Germany), Department of Prosthetic Dentistry, and (2) Center of Dental Medicine, University of Zürich (Switzerland), Clinic for Fixed and Removable Prosthodontics and Dental Material Science. The study protocol was approved by the ethics committee of the Canton of Zürich (StV 08/10) and by the ethics commission of the Medical Center Freiburg (241/08). The study was registered in the German Clinical Trials Register (ID: DRKS00000226) and is, therefore, available in the World Health Organization (WHO) International Clinical Trials Registry Platform. Informed consent was obtained from all patients prior to their inclusion. Recruitment was done between April 2010 and July 2012. This multicenter study was designed and performed considering the Strengthening the Reporting of Observational Studies in Epidemiology (STROBE) Statement for cohort studies (http://www.strobe-statement.org).

\section{Participants}

Sixty partially edentulous patients asking for an implant-supported, single-tooth restoration or a three-unit fixed dental prosthesis (FDP), irrespective of the jaw, were recruited, provided they were 20-70 years old, showed a good health status, were compliant, were in need of an implant-supported restoration, had sufficient bone volume in the area of interest, showed a stable occlusal relationship, and no signs of pronounced bruxism (such as attritions and fractures on the natural teeth or reconstructions, no pain on muscular palpation, no paincausing joint sound, and no self-reported clenching habits). Reasons for exclusion were alcohol or drug abuse, smoking of more than 10 cigarettes per day, severe bruxism or other destructive habits, and health conditions not permitting the surgical procedure.

The supporting cylindroconical and screw-type, one-piece zirconia implants (ceramic.implant prototype; vitaclinical, VITA Zahnfabrik; Bad Säckingen, Germany) comprised platforms of 4.0, 4.5, and $5.5 \mathrm{~mm}$. The surgical procedures and the methodology for measuring the tissue response have been described earlier [15]. In total, 60 patients were recruited to receive 11 FDPs and 49 SCs. To obtain a clear indication for the present evaluation of posterior single crowns, three patients with three anterior crowns were excluded from the analysis. Eleven FDPs in 11 patients were not evaluated, because feldspathic veneered FDPs on zirconia implants do not conform to the manufacturer's recommendation. 


\section{Clinical and laboratory procedures}

Information on the clinical and laboratory procedures was provided in detail in precedent publications reporting preliminary results after 12 months of observation [15, 16]. Key points were as follows. The implants were immediately temporized with prefabricated provisional reconstructions comprising slight occlusal contacts (shimstock foil of $8 \mu \mathrm{m}$ thickness could be pulled through). After a healing period of at least 8 (mandible) or 16 weeks (maxilla), respectively, impressions were taken (Impregum; 3M Espe, Seefeld, Germany) and digitized (inEos scanner; Sirona, Bensheim, Germany). CAD/CAM-fabricated (Cerec inLab ${ }^{\circledR}$ software, inLab $^{\circledR}$ MC XL 4-axis milling device; Sirona) zirconia frameworks (In-Ceram YZ, VITA Zahnfabrik) were hand-layered with a leucite-reinforced feldspathic ceramic (VM9, VITA Zahnfabrik) according to the manufacturer's instructions. All SCs were adhesively cemented using a dual-curing resin cement (RelyX Unicem Aplicap; 3M Espe). In case of a subgingival cementation line, retraction cords were placed to facilitate cement removal. Centric and dynamic occlusions were controlled (12 $\mu \mathrm{m}$ occlusion foil, $8 \mu \mathrm{m}$ shimstock foil) both on the restoration and the residual dentition to avoid any excessive forces.

\section{Baseline and follow-up examinations}

At baseline (post-cementation) and again after 6, 12, 24, and 36 months of function, the restorations were examined clinically. These appointments included (1) a visual and tactile inspection of the restorations, (2) a control of static and dynamic occlusion, (3) impression taking, and (4) intraoral photographs of the restorations and neighboring teeth. Biological and technical complications were documented and the required treatment applied, if necessary.

\section{Clinical outcome}

The restorations were evaluated in five categories (framework fracture, chipping of the veneering ceramic, occlusal roughness, marginal integrity, and contour of the restoration; Table 1) according to modified USPHS criteria [17]. SCs within a range of excellence were rated Alpha, whereas SCs showing minor deviations from the ideal were judged to be Bravo. SCs showing clinically unacceptable defects that could be intraorally repaired to a clinically acceptable level were rated Charlie. In case of an irreparable problem of clinical relevance, a restoration was rated Delta. A successful SC was not allowed to comprise any Charlie or Delta rating, whereas Charlie ratings were accepted for survival. Any Delta rating in a single category resulted in the restoration judged a failure. 


\section{Patient-reported outcome}

Visual analog scales (VAS) were applied to evaluate the patient's appraisal of function, esthetics and appearance, sense, speech, and self-esteem. At the timepoint of study inclusion, at final prosthesis insertion, and at every follow-up appointment, the patients were asked to label a point on a line that corresponded with their personal satisfaction in each aforementioned category. The line was $10 \mathrm{~cm}$ in length, without scale, and every millimeter corresponded to $1 \%$ of satisfaction (i.e., $10 \mathrm{~cm}$ corresponded to $100 \%$ ). The left endpoint represented poor satisfaction $(0 \%)$, whereas the point at the right end represented excellent satisfaction (100\%). Finally, the patient's markings were measured with a ruler.

\section{Statistical analyses}

Sample size calculation (60 patients) was performed considering the radiographic outcome (expected marginal bone loss known from the literature) and was, therefore, not primarily designed for the evaluation of the prosthetic outcome [15]. Means, medians, and standard deviations were computed for descriptive analyses of the data. Kaplan-Meier survival and success estimates were calculated and graphically presented using plots. Moreover, log-rank tests were used to check for an influence of co-variables (gender, jaw, and center). A Wilcoxon matched-pairs signed-rank test was used to calculate for changes between prosthetic delivery and the follow-ups (USPHS criteria, PROMs). All calculations were performed with the STATA 14.2 (StataCorp LT, College Station, TX, USA) statistical software. The probability level for statistical significance was set to $\mathrm{p}<0.05$. 


\section{Results}

\section{Status of follow-up}

Of the 46 patients with posterior implant-supported single crowns (SCs), one patient lost his implant 5 weeks after implant insertion, and another patient refused to participate in further follow-ups after insertion of the final crown, for unknown reasons. For the evaluation of the prosthesis, both were regarded as drop-outs. Therefore, 44 patients (19 females, 25 males) provided with 44 posterior SCs located in the region of a former premolar $(n=17)$ or molar $(n$ $=27$ ) remained for evaluations and analyses [16]. Of these restorations, 29 were opposed by solely natural teeth, nine by restored teeth or a combination of a restored and a natural tooth, three by tooth-supported FDPs, two by implant-supported FDPs and one by a tooth-retained removable dental prosthesis.

The final restorations were delivered between April 2010 and February 2012. The mean patient age at prosthetic delivery was $46.6 \pm 13.1$ years (range: $25-69$ years). Of the 44 included patients, 40 patients with 40 SCs were seen at the 3-year follow-up between May 2013 and April 2015 (Fig. 1), resulting in a mean observation time of $36.7 \pm 1.2$ months. One patient missed the 3-year appointment but will be available for further follow-ups. Two patients refused further participation in the study after the 1-year follow-up and one more patient after the 2-year follow-up. The patients gave no reason for study withdrawal. For the 3-year analyses, these four patients/SCs were considered drop-outs.

\section{Clinical outcome}

No SC had to be replaced, resulting in $100 \%$ survival. Minor technical complications were frequently observed, however. Compared to the evaluations at final prosthesis insertion, the occurrence of chipping of the veneering ceramic (12 minor chippings, 2 major chippings; $\mathrm{p}=$ 0.0005; Fig. 1/1e) and of occlusal roughness (27 SCs with a small area of occlusal roughness; $\mathrm{p}=0.0003$; Fig. 1/3e) was statistically significant after 3 years of service. Moreover, a significant incidence of marginal disintegration was found (six SCs with a slightly soundable marginal gap, one SC with a significant crevice; $\mathrm{p}=0.0253$ ).

Based on the definition of success (Table 1) and the evaluations at prosthetic delivery and the follow-ups (Table 2), Kaplan-Meier success estimates were calculated and presented as plots (Fig. 2) [18]. Overall, the calculated Kaplan-Meier success estimate was $87.5 \pm 5.3 \%$ ( \pm Std. error). The performed log-rank tests revealed no statistically significant differences for the success curves regarding jaw ( $\mathrm{p}=0.345$; maxilla: $94.4 \pm 5.4 \%$, mandible: $83.3 \pm 7.8 \%$ ), 
gender ( $\mathrm{p}=0.891$; females: $89.5 \pm 7.0 \%$, males: $85.9 \pm 7.8 \%)$, and center $(\mathrm{p}=0.255$; center 1 : $94.7 \pm 5.1 \%$, center $2: 81.7 \pm 8.6 \%$ ).

No framework fracture or loss of retention was observed. The cementation line was found to be subgingival in most of the cases (mean: $0.3 \pm 0.7 \mathrm{~mm}$ ), particularly in proximal areas. For the final restorations, no cement residuals were found on the $\mathrm{X}$-rays in proximal areas.

The three anterior crowns, excluded from the analyses as mentioned earlier, were surviving and successful after 3 years of observation. Of the 11 FDPs, two had to be replaced after 181 and 187 days of service.

\section{Patient-reported outcome (VAS)}

Compared to the surveys before any treatment, all interrogations (function: $+18.3 \%$, esthetic: $+22.2 \%$, self-esteem: $+15.6 \%$; $\mathrm{p}<0.001)$ except the appraisal of speech $(+0.8 \% ; \mathrm{p}=0.139)$ showed significantly improved VAS scores when the final SC was inserted (81-93.6\%, Fig. 3 , Table 3). These improvements remained unaffected until the end of the 3-year follow-up $(85.4-92.7 \%, \mathrm{p}>0.390)$. 


\section{Discussion}

The international ISO standard 6872 ("Dentistry - Ceramic materials") defines five classes of dental ceramic materials for the fabrication of fixed prostheses by intended clinical use with required mechanical (flexural strength $[\mathrm{MPa}]$ ) and chemical (solubility $\left[\mu \mathrm{g} / \mathrm{cm}^{2}\right]$ ) properties. The evaluated materials of the present investigation fulfill the requirements of the appropriate class. Because laboratory tests are limited in simulating clinical reality, clinical trials are deemed necessary for a final verification of specific indications such as implant-supported posterior single crowns. This trial revealed a $100 \%$ survival rate and high patient satisfaction with zirconia-based, all-ceramic single crowns supported by one-piece zirconia implants. However, a significant incidence of veneer fractures and occlusal roughness resulted in a frequent occurrence of technical complications. Two major chippings, one significant marginal opening and one pronounced over-contouring, resulted in a reduced KM success estimate of $87.5 \%$ after 36 months of observation.

Regrettably, data on how to restore zirconia oral implants installed in posterior regions for the replacement of single missing teeth is still rare. To date, only one study is available prospectively evaluating bi-layer crowns [14]. In that study, 63 zirconia-based SCs (Procera Zirconia, NobelRondo Zirconia; Nobel Biocare, Gothenburg, Sweden) supported by ceramic implants from the same manufacturer (Nobel Biocare) were analyzed after 5 years of observation. Sixty crowns were located in the area of premolars or molars. After a follow-up of 36 months, the success rate of these restorations was $71 \%$ (95\% CI: 61-83\%). However, only chipping was considered for non-success with more stringent criteria (even minor chippings resulted in non-success). Therefore, one cannot simply compare the reported success rates with the present findings. Applying the same success criteria to our data set, the chipping-free KM estimate results in 76\% (95\% CI: 58-86\%), suggesting a comparable outcome. However, no replacements were necessary up to date in the present study, compared to a failure/replacement rate of $23.4 \%$ at the end of follow-up when using NobelRondo for veneering in our previous study [14]. One might conclude that the evaluated leucitereinforced feldspathic veneering ceramic used in the present investigation was not capable to reduce the chipping frequency but indeed in reducing the severity of this complication, thereby successfully avoiding the need for replacements within the first three years of observation. Concerning the literature, an increased flexural strength of the veneering ceramic and a slightly higher mismatch of the coefficient of thermal expansion (as mentioned earlier) might be responsible for this finding [19, 20]. 
Because data on zirconia implant-supported SCs is rare, zirconia-based all-ceramic SCs cemented to the abutments of two-piece titanium implants might be suitable for further comparison. In a split-mouth design, Güncü and colleagues evaluated 48 tooth- and implantsupported SCs composed of zirconia copings (LAVA; 3M Espe, St. Paul, USA) veneered with the same feldspathic porcelain (Vita VM9) as used in the present study [21]. All crowns were located in posterior regions. After 4 years of observation, $91.7 \%$ of the 24 implantsupported SCs were deemed successful. Again, criteria for success differed significantly from the criteria applied in the present study. Only a major chipping resulting in the need for replacement was considered a failure. Minor chippings and occlusal roughness were not recorded. Similar to our findings, a tendency toward marginal disintegration was observed. Whereas marginal integrity was rated excellent at $87.5 \%$ of the implant-supported restorations at baseline, this value decreased to $74 \%$ at the 4-year follow-up. Hence, the provided data on the technical outcome can be considered comparable to our results. In a retrospective study, Nejatidanesh and co-workers evaluated 232 cemented implant-supported SCs placed in 122 patients after a mean exposure time of 59.2 months [22]. Fracture of the veneering ceramic occurred in $8.2 \%$ of the restorations ( $\mathrm{n}=19 ; 7$ anterior, 12 posterior), and two replacements were necessary. This outcome appears to be superior to the present investigation. Nevertheless, evaluating minor complications retrospectively might not be as sensitive as prospective evaluations. Previous publications evaluating the same material composition (Cercon/Cercon Ceram Kiss; DeguDent, Hanau, Germany) in a comparable setup found significantly higher complication rates of $7.5 \%$ after 6 months and $24.5 \%$ after two years, respectively [9, 23]. Furthermore, the patient-reported outcome was assessed in this trial [22], revealing a high patient satisfaction, as observed in the present investigation. However, the patients were surveyed only once after the treatment. Missing pre-treatment data results in a limited validity of the patient-reported outcome, not allowing for the objective conclusion of an improved satisfaction.

Cacaci and colleagues determined the clinical outcome of an alternative veneering technique [24]. This technique consisted of pressed veneer caps made from lithium disilicate fused to zirconia substructures for the production of single implant-supported posterior crowns. A total of 114 implants were restored with single crowns, among those, 61 cemented and 53 screwretained restorations. Only two chippings were reported (3.3\%) for cemented SCs after a mean observation period of 36 months, resulting in a favorable outcome when compared to the present findings. However, efforts needed for the production of such single crowns might be considered uneconomic because the ceramic material used for the production of the 
veneering cap showed a comparable outcome when applied monolithically and without any supporting substructure [25]. In another clinical trial, 24 zirconia implant-supported SCs made from lithium disilicate showed no chippings after a mean observation period of 31 months [26]. However, the same tendency in developing occlusal roughness was found [25, 26].

Besides chipping and occlusal roughening of the veneering ceramic, a significant incidence of marginal disintegration was found $(\mathrm{p}=0.0253)$. Compared to the baseline data postcementation, five more restorations showed a slightly soundable marginal gap. This might be due to a compromised fit of early CAD/CAM substructures, as reported for tooth-supported restorations and thought to be responsible for increased rates of secondary caries [4], and a potential occurrence of cement washout. It remains to be seen whether marginal opening increases during the further observation period of the present investigation and how far it can be overcome by using newer five-axis milling devices in upcoming clinical investigations. To the present follow-up, this marginal opening did not result in biological complications (e.g., gingival inflammation or increased marginal bone loss compared to unaffected restorations).

Finally, the missing control group (e.g., porcelain fused to metal SCs supported by two-piece titanium implants) represents a major limitation of the present study. Therefore, one cannot conclude that the presented findings show superiority or inferiority of this treatment protocol compared to conventional types of restorations as mentioned earlier. It has to be assumed that the highly accepted patient-centered outcome was derived from rehabilitation of posterior support instead of the applied ceramic materials.

\section{Conclusions}

Posterior zirconia-based SCs supported by zirconia oral implants entirely survived the followup period of three years and satisfied patients' needs highly. However, technical complications resulted in a reduced success rate. Monolithic approaches might be able to overcome this issue. In further clinical research, it is recommended to evaluate such crowns for a time- and cost-effective restoration of one-piece zirconia oral implants installed in posterior areas.

\section{Acknowledgments}

This investigation was supported by VITA Zahnfabrik, Bad Säckingen, Germany. I. Sailer, B. Spies, R. Kohal and R. Jung serve as lecturers for VITA Zahnfabrik. The authors declare no further conflict of interest. 


\section{Literature}

[1] R.A. Jordan, C. Bodechtel, K. Hertrampf, T. Hoffmann, T. Kocher, I. Nitschke, U. Schiffner, H. Stark, S. Zimmer, W. Micheelis, The Fifth German Oral Health Study (Fünfte Deutsche Mundgesundheitsstudie, DMS V) - rationale, design, and methods, BMC Oral Health 14(1) (2014) 161.

[2] H. Stark, I. Nitschke, Disease- and treatment prevalence in younger adults (aged 35 to 44 years) - Tooth loss and prosthetic rehabilitation, in: A.R. Jordan, W. Micheelis (Eds.), The Fifth German Oral Health Study (DMS V), Institute of German Dentists (IDZ), Cologne, 2016, pp. 335-358.

[3] I. Nitschke, H. Stark, Disease- and treatment prevalence in younger elderly (aged 65 to 74 years) - Tooth loss and prosthetic rehabilitation, in: A.R. Jordan, W. Micheelis (Eds.), The Fifth German Oral Health Study (DMS V), Institute of German Dentists (IDZ), Cologne, 2016, pp. 416-451.

[4] I. Sailer, N.A. Makarov, D.S. Thoma, M. Zwahlen, B.E. Pjetursson, All-ceramic or metalceramic tooth-supported fixed dental prostheses (FDPs)? A systematic review of the survival and complication rates. Part I: Single crowns (SCs), Dent. Mater. 31(6) (2015) 603-23.

[5] K. Tan, B.E. Pjetursson, N.P. Lang, E.S.Y. Chan, A systematic review of the survival and complication rates of fixed partial dentures (FPDs) after an observation period of at least 5 years, Clin. Oral Implants Res. 15(6) (2004) 654-666.

[6] D. Edelhoff, J.A. Sorensen, Tooth structure removal associated with various preparation designs for posterior teeth, Int. J. Periodontics Restorative Dent. 22(3) (2002) 241-9.

[7] L. Hjalmarsson, M. Gheisarifar, T. Jemt, A systematic review of survival of single implants as presented in longitudinal studies with a follow-up of at least 10 years, Eur. J. Oral. Implantol. 9(Suppl 1) (2016) 155-62.

[8] S. Pieralli, R.J. Kohal, R.E. Jung, K. Vach, B.C. Spies, Clinical outcomes of zirconia dental implants, J. Dent. Res. 96(1) (2017) 38-46. 
[9] S. Schwarz, C. Schröder, A. Hassel, W. Bömicke, P. Rammelsberg, Survival and chipping of zirconia-based and metal-ceramic implant-supported single crowns, Clin. Implant Dent. Relat. Res. 14 (Suppl 1) (2012) 119-25.

[10] C. Larsson, A. Wennerberg, The clinical success of zirconia-based crowns: a systematic review, Int. J. Prosthodont. 27(1) (2014) 33-43.

[11] M.V. Swain, Unstable cracking (chipping) of veneering porcelain on all-ceramic dental crowns and fixed partial dentures, Acta Biomater. 5(5) (2009) 1668-77.

[12] N. Higaki, T. Goto, Y. Ishida, M. Watanabe, Y. Tomotake, T. Ichikawa, Do sensation differences exist between dental implants and natural teeth?: a meta-analysis, Clin. Oral Implants Res. 25(11) (2014) 1307-1310.

[13] D.J. Mahmood, E.H. Linderoth, A. Wennerberg, P. Vult Von Steyern, Influence of core design, production technique, and material selection on fracture behavior of yttriastabilized tetragonal zirconia polycrystal fixed dental prostheses produced using different multilayer techniques: split-file, over-pressing, and manually built-up veneers, Clin Cosmet Investig Dent 8 (2016) 15-27.

[14] B.C. Spies, S. Stampf, R.J. Kohal, Evaluation of Zirconia-Based All-Ceramic Single Crowns and Fixed Dental Prosthesis on Zirconia Implants: 5-Year Results of a Prospective Cohort Study, Clin. Implant Dent. Relat. Res. 17(5) (2015) 1014-28.

[15] R.E. Jung, P. Grohmann, I. Sailer, Y.-N. Steinhart, A. Fehér, C. Hämmerle, J.R. Strub, R. Kohal, Evaluation of a one-piece ceramic implant used for single-tooth replacement and three-unit fixed partial dentures: a prospective cohort clinical trial, Clin. Oral Implants Res. 27(7) (2016) 751-761.

[16] B.C. Spies, R.J. Kohal, M. Balmer, K. Vach, R.E. Jung, Evaluation of zirconia-based posterior single crowns supported by zirconia implants: preliminary results of a prospective multicenter study, Clin. Oral Implants Res. (2016).

[17] J.F. Cvar, G. Ryge, Reprint of criteria for the clinical evaluation of dental restorative materials. 1971, Clin. Oral Investig. 9(4) (2005) 215-32.

[18] E.L. Kaplan, P. Meier, Nonparametric Estimation from Incomplete Observations, Journal of the American Statistical Association 53(282) (1958) 457-481. 
[19] J. Fischer, B. Stawarczyk, C.H.F. Hämmerle, Flexural strength of veneering ceramics for zirconia, J. Dent. 36(5) (2008) 316-321.

[20] J. Fischer, B. Stawarzcyk, A. Trottmann, C.H. Hämmerle, Impact of thermal misfit on shear strength of veneering ceramic/zirconia composites, Dent. Mater. 25(4) (2009) 41923.

[21] M.B. Güncü, U. Cakan, G. Aktas, G.N. Güncü, Ş. Canay, Comparison of implant versus tooth-supported zirconia-based single crowns in a split-mouth design: a 4-year clinical follow-up study, Clin. Oral Investig. 20(9) (2016) 2467-2473.

[22] F. Nejatidanesh, H. Moradpoor, O. Savabi, Clinical outcomes of zirconia-based implantand tooth-supported single crowns, Clin. Oral Investig. 20(1) (2016) 169-178.

[23] F.P. Nothdurft, P.R. Pospiech, Zirconium dioxide implant abutments for posterior singletooth replacement: first results, J. Periodontol. 80(12) (2009) 2065-72.

[24] C. Cacaci, F. Cantner, T. Mücke, P. Randelzhofer, J. Hajtó, F. Beuer, Clinical performance of screw-retained and cemented implant-supported zirconia single crowns: 36-month results, Clin. Oral Investig. (2016).

[25] D.S. Thoma, F. Brandenberg, V. Fehmer, D.L.E. Büchi, C.H.F. Hämmerle, I. Sailer, Randomized Controlled Clinical Trial of All-Ceramic Single Tooth Implant Reconstructions Using Modified Zirconia Abutments: Radiographic and Prosthetic Results at 1 Year of Loading, Clin. Implant Dent. Relat. Res. 18(3) (2016) 462-472.

[26] B.C. Spies, S.B. Patzelt, K. Vach, R.J. Kohal, Monolithic lithium-disilicate single crowns supported by zirconia oral implants: three-year results of a prospective cohort study, Clin. Oral Implants Res. 27(9) (2016) 1160-8. 


\section{Figure legends}

Fig. 1: Three representative cases (1-3) at the time point of final prosthesis insertion $(a-c)$ and after 3 years of observation (d, e). Restoration 1 showed a minor chipping at the disto-buccal aspect at the three-year follow-up (1e). Restoration 2 was free of any complication. Restoration 3 was affected by a minor occlusal roughness.

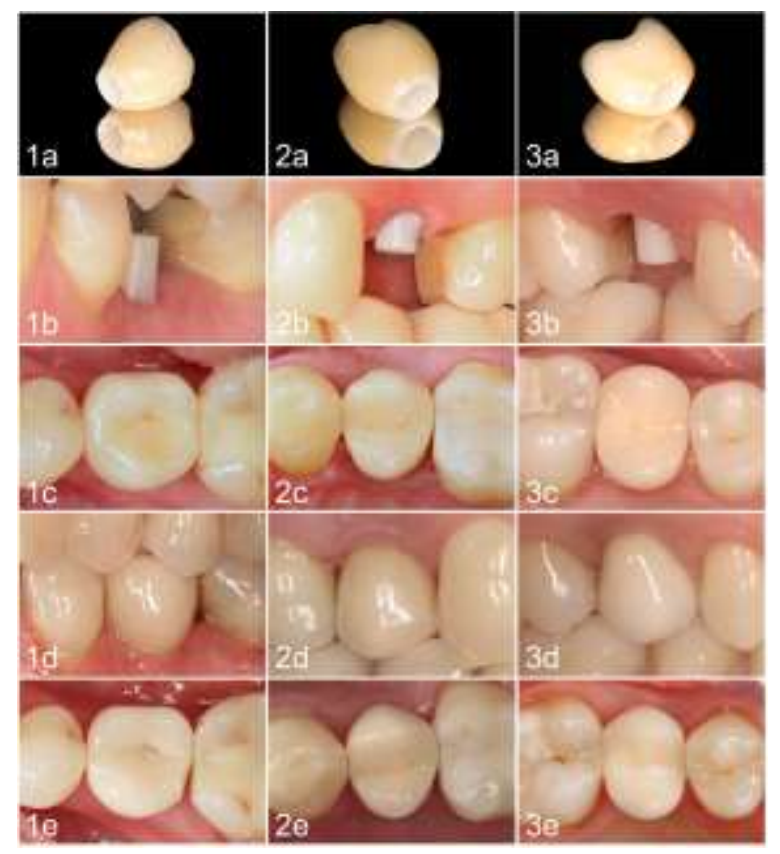

Fig. 2: Kaplan-Meier success plots (a: overall; b-d: stratified by jaw, gender, and center).

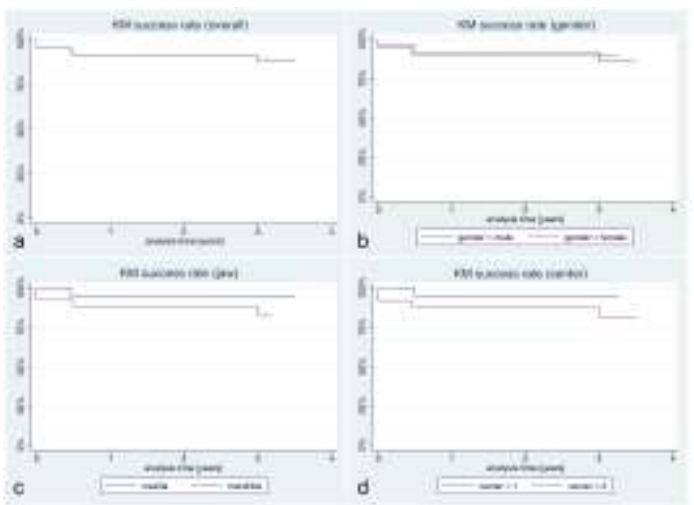


Fig. 3: Box plots of the patient-reported outcome measures (VAS score [\%]; a:

function/eating; b: esthetics; c: sense; d: speech; e: self-esteem) before treatment (PT:

pretreatment), at the delivery of the prosthetic restoration (PD: prosthetic delivery) and the follow-up appointments (1y: 1-year follow-up; 3y: 3-year follow-up).

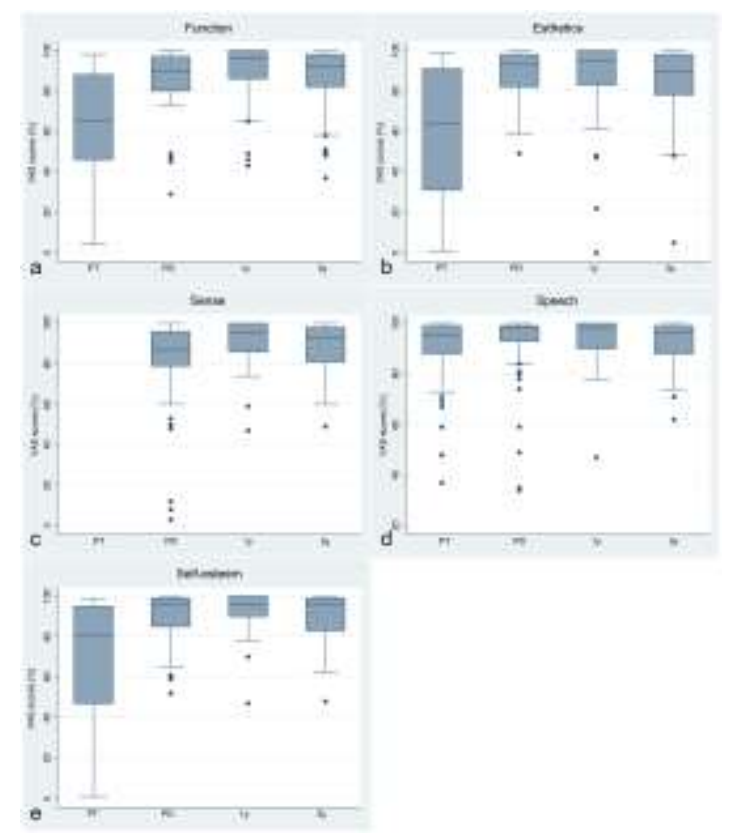


Tab. 1: Modified USPHS criteria for the success and survival analyses of the restorations

\begin{tabular}{|c|c|c|c|c|}
\hline & Alpha (A) & Bravo (B) & Charlie (C) & Delta (D) \\
\hline $\begin{array}{l}\text { Fracture of } \\
\text { framework }\end{array}$ & No fracture & - & - & $\begin{array}{l}\text { Fracture } \\
\text { (Loss of } \\
\text { reconstruction) }\end{array}$ \\
\hline $\begin{array}{l}\text { Fracture of } \\
\text { veneering } \\
\text { ceramic }\end{array}$ & No fracture & $\begin{array}{l}\text { Minor chipping } \\
\text { (polishable) }\end{array}$ & $\begin{array}{l}\text { Major chipping } \\
\text { (up to framework) }\end{array}$ & $\begin{array}{l}\text { Fracture } \\
\text { (Loss of } \\
\text { reconstruction) }\end{array}$ \\
\hline $\begin{array}{l}\text { Occlusal } \\
\text { roughness }\end{array}$ & No roughness & $\begin{array}{l}\text { Slight roughness } \\
(\varnothing<2 \mathrm{~mm})\end{array}$ & $\begin{array}{l}\text { Obvious roughness } \\
(\varnothing>2 \mathrm{~mm})\end{array}$ & $\begin{array}{l}\text { Reconstruction needs } \\
\text { to be replaced }\end{array}$ \\
\hline $\begin{array}{l}\text { Marginal } \\
\text { integrity }\end{array}$ & $\begin{array}{l}\text { No visible or } \\
\text { soundable gap }\end{array}$ & $\begin{array}{l}\text { Marginal gap } \\
\text { slightly } \\
\text { soundable }\end{array}$ & $\begin{array}{l}\text { Explorer } \\
\text { penetrates a } \\
\text { significant crevice }\end{array}$ & $\begin{array}{l}\text { Reconstruction needs } \\
\text { to be replaced }\end{array}$ \\
\hline \multirow[t]{2}{*}{$\begin{array}{l}\text { Contour of } \\
\text { reconstruction }\end{array}$} & $\begin{array}{l}\text { Perfectly } \\
\text { contoured }\end{array}$ & $\begin{array}{l}\text { Slightly under- / } \\
\text { overcontoured }\end{array}$ & $\begin{array}{l}\text { Pronounced under- } \\
\text { / overcontouring }\end{array}$ & $\begin{array}{l}\text { Reconstruction } \\
\text { inacceptable }\end{array}$ \\
\hline & Success & & Survival & Failure \\
\hline
\end{tabular}

Tab. 2: Results of the single crown evaluations according to the modified USPHS criteria (Tab. 1) at prosthetic delivery and the follow-ups. Significance (Wilcoxon matchedpairs signed-rank test) was calculated for changes between delivery and the 3-year follow-up.

\begin{tabular}{|c|c|c|c|c|c|}
\hline & $\begin{array}{l}\text { Framework } \\
\text { fracture } \\
n \text { (Alpha / } \mathrm{Br}\end{array}$ & $\begin{array}{l}\text { Chipping of } \\
\text { veneering } \\
\mathrm{O} / \text { Charlie / D }\end{array}$ & $\begin{array}{l}\text { Occlusal } \\
\text { roughness } \\
\text { lta) }\end{array}$ & $\begin{array}{l}\text { Marginal } \\
\text { integrity }\end{array}$ & Contour \\
\hline Delivery & $44(44 /-/-/-)$ & 44 (43/1/-/-) & $44(31 / 13 /-/-)$ & $44(42 / 1 / 1 /-)$ & $44(19 / 24 / 1 /-$ \\
\hline 6m Follow-up & $44(44 /-/-/-)$ & $44(39 / 4 / 1 /-)$ & $\begin{array}{l}44(22 / 21 / 1 /- \\
)\end{array}$ & $44(41 / 2 / 1 /-)$ & $\begin{array}{l}44(23 / 20 / 1 /- \\
)\end{array}$ \\
\hline $\begin{array}{l}\text { 12m Follow- } \\
\text { up }\end{array}$ & 44 (44/-/-/-) & $44(36 / 7 / 1 /-)$ & $44(18 / 26 /-/-)$ & $44(40 / 3 / 1 /-)$ & $\begin{array}{l}44(19 / 24 / 1 /- \\
)\end{array}$ \\
\hline $\begin{array}{l}24 m \text { Follow- } \\
\text { up }\end{array}$ & 42 (42/-/-/-) & $42(33 / 8 / 1 /-)$ & $42(14 / 28 /-/-)$ & $42(38 / 3 / 1 /-)$ & $42(17 / 24 / 1 /-$ \\
\hline $\begin{array}{l}\text { 36m Follow- } \\
\text { up }\end{array}$ & $40(40 /-/-/-)$ & $\begin{array}{l}40(26 / 12 / 2 /- \\
)\end{array}$ & $40(13 / 27 /-/-)$ & $40(33 / 6 / 1 /-)$ & $\begin{array}{l}40(18 / 21 / 1 /- \\
)\end{array}$ \\
\hline Significance & - & 0.0005 & 0.0003 & 0.0253 & 0.7815 \\
\hline
\end{tabular}


Tab. 3: Patient assessments of function (eating), esthetics and appearance, sense ("feeling like my own teeth"), speech and self-esteem (VAS, [\%]) before treatment (P), at the delivery of the final restoration (D) and the follow-up appointments (1y, 3y).

Significance (Wilcoxon rank-sum test) was calculated for changes between P and D (except for sense) as well as D and $3 y$ to verify a lasting effect.

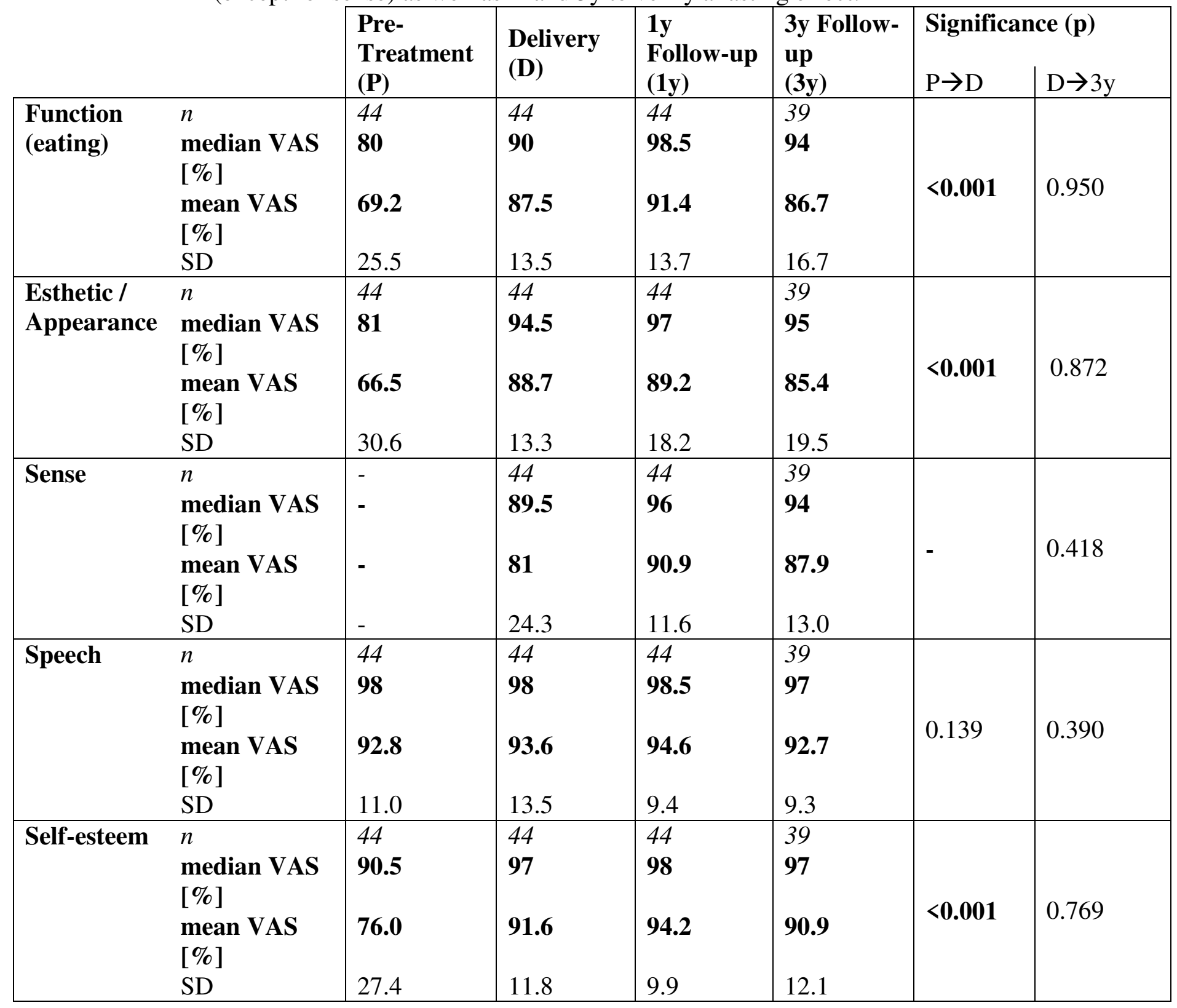

